INVESTIGATIONES LINGUISTICAE VOL. XXII, 2010

(C) INSTITUTE OF LINGUISTICS - ADAM MICKIEWICZ UNIVERSITY

AL. NIEPODLEGŁOŚCI 4, 60-874, POZNAŃ - POLAND

\title{
Wymiary kultury a grzeczność w języku
}

\section{Cultural dimensions and linguistic politeness}

\author{
Anna Zięba \\ Instytut Językoznawstwa, Uniwersytet im. Adama Mickiewicza \\ ul. Aleja Niepodległości 4, 61-874 Poznań \\ azieba@amu.edu.pl
}

\begin{abstract}
This article dwells on the relationship between expressions of politeness such as forms of address, greetings and parting phrases, apologies, advice, curses, etc. and cultural differences presented within the framework of Geert Hofstede's 5D model. The author discusses the impact that culture has on politeness in language and proves her point by giving examples of the influence of individualism and collectivism, power distance, femininity and masculinity as well as uncertainty avoidance on the way politeness is expressed in different cultures. Also the relationship between the usage of plural and singular form is studied.
\end{abstract}

\section{Wstęp}

Celem niniejszego artykułu jest odpowiedź na pytanie czy, i jeśli tak, to w jakim stopniu, kultura narodowa wpływa na formy grzecznościowe występujące $\mathrm{w}$ różnych językach. Podane przykłady zaczerpnięte zostaną $\mathrm{z}$ języka polskiego, angielskiego, niemieckiego, francuskiego, szwedzkiego, węgierskiego, czeskiego, rosyjskiego, holenderskiego, hiszpańskiego, portugalskiego, wietnamskiego, japońskiego oraz $\mathrm{z}$ języków arabskich. Ramę teoretyczną dla badania stanowić będzie teoria wymiarów 
kultury Geerta Hofstedego (2000). Przytoczone wartości ${ }^{1}$ podane będą w procentach, przy założeniu, że dla dystansu do władzy (PDI) o\% to dystans minimalny, a 100\% maksymalny. W wymiarze indywidualizm/kolektywizm (IDV) $0 \%$ oznacza skrajny kolektywizm, a 100\% skrajny indywidualizm. W wymiarze kobiecość/męskość (MAS), o\% to skrajna kobiecość, a 100\% to skrajna męskość. W wymiarze unikania niepewności (UAI) o\% oznaczać będzie minimalne unikanie niepewności, a 100\% maksymalne.

\section{Dystans do władzy}

W krajach o małym dystansie do władzy komunikujące się osoby nie podkreślają wyższości żadnej ze stron. Partnerskie układy w rodzinie, szkole czy pracy, mają swoje odbicie w sposobie komunikacji osób wychowanych w tych krajach. Dzieci często mówią do rodziców po imieniu; w szkole, gdy czegoś nie rozumieją, pytają. Pracownicy nie maja problemu ze zwracaniem się do przetożonych (ibid.: 67). Są to kraje, gdzie sprzeciw osoby znajdującej się niżej w hierarchii jest dopuszczalny.

Wymiar ten Hofstede określa jako „stosunek do zjawiska nierówności między ludźmi w różnych krajach” (2000, s. 63), dotyczy on więc relacji między osobami o różnym statusie, pozycji czy stanowisku.

Przykładem kraju o kulturze małego dystansu może być z pewnością Wielka Brytania (PDI 35\%). Osoby wychowane $\mathrm{w}$ tej kulturze nie czują potrzeby pouczania innych czy podkreślania swego miejsca w społecznej hierarchii, nie wdają się również w długie dysputy. Angielski zwrot powitalny Hello! używany jest zarówno w kontaktach oficjalnych jak i nieoficjalnych. Inaczej niż w językach słowiańskich: polskie Cześć!, czeskie Ahoj!, czy rosyjskie Привеm! używane są jedynie w kontaktach nieoficjalnych, natomiast w oficjalnych używa się zwrotów: Dzień dobry!, Dobrý den! i Здравствуйте!. Wynikiem małego dystansu do władzy w Wielkiej Brytanii może być również nieprzenoszenie tytułów służbowych na grunt prywatny (cf. Szostkiewicz, 2005, s. 92).

Innym krajem o małym dystansie do władzy jest USA (PDI 40\%). Jak zauważa Warakomska (2005) nawet treść tabliczek informacyjnych przyjmuje tu raczej ton prośby niż zakazu czy nakazu:

Nie ma napisu: "Rozmowy przez telefon komórkowy zabronione", tylko "Proszę, powstrzymaj się od rozmów przez telefon komórkowy" lub: "Staraj się nie przeszkadzać innym, przycisz telefon". Również [na ulicach] nie ma tabliczek z napisem: „Nie wolno deptać trawników”, tylko „Unikaj chodzenia po trawie” (ibid., s. 281).

Mały dystans do władzy można zaobserwować także w języku niemieckim (PDI $35 \%)$, w którym występuje niewiele, w porównaniu na przykład z językiem polskim (PDI 68\%), form tytularnych:

W kontaktach twarzą w twarz są stosowane w zasadzie tylko dwa tytuły naukowe: Doktor i Profesor, oraz tytuły wyższych urzędników państwowych, np. Ministerialdirektor albo Minister, i to z reguły tylko jednorazowo na początku rozmowy. W trakcie wymiany zdań obowiązuje już obie strony zaimek osobowy Sie jako forma adresatywna, choćby nawet jednym z rozmówców był sam kanclerz (Tomiczek, 2005, s. 58).

Ponadto w Niemczech używa się faktycznych, a nie pełnych, tytułów, np. Herr Vizedirektor (zamiast Herr Direktor) (cf. ibid., s. 6o) i nie przypomina innym o ich obowiązkach $\mathrm{w}$ pracy, ponieważ takie zachowanie równe byłoby kwestionowaniu ich profesjonalizmu (Nagórko, 2005, s. 82).

\footnotetext{
${ }^{1}$ Wartości te zostały opublikowane przez G. Hofstedego po raz pierwszy w 1991r. w Kultury i organizacje. Zaprogramowanie umystu, a następnie uzupełnione i umieszczone na jego stronie internetowej: www.geerthofstede.com. Podane w artykule wartości pochodzą ze strony internetowej.
} 
Kolejnym językiem o znikomej liczbie form tytularnych jest holenderski (PDI 38\%). Używane są jedynie tytuły „profesor” i „doktor”. W Szwecji (PDI 31\%), jedynymi obowiązującymi tytułami są tytuły naukowe.

Oczywistym wydaje się wpływ dystansu do władzy na użycie bezpośrednich form adresatywnych. W krajach anglojęzycznych, do współrozmówców zwracamy się przez zaimek you. Jest to forma wyrażająca szacunek do interlokutorów, sugerująca, iż niezależnie od warstwy społecznej, każdy jest równy. Istnieją oczywiście zwroty madame i sir, choć ich użycie ograniczone jest do niewielu kontekstów.

W Holandii (PDI 38\%), używa się przede wszystkim formy je 'ty'. Do członków rodziny zwraca się po imieniu. W Szwecji (PDI 31\%) nie istnieje inna forma adresatywna niż „ty”. Do wszystkich, bez względu na wiek, status czy pozycję mówi się po imieniu.

W niemieckim, z kolei, istnieją dwie formy zwracania się do współrozmówców: Sie (3 os. lm.) i du (2 os. lp.). Aby móc zwracać się do kogoś per „ty” należy najpierw uzyskać jego przyzwolenie. Co ciekawe, forma pośrednia np. Hans, darf ich Sie bitten? jest coraz chętniej używana (cf. Tomiczek, 2005, s. 54-56).

We Włoszech, kraju o umiarkowanym dystansie do władzy (PDI 50\%), istnieje tendencja do częstego zwracania się do innych osób per „ty”, szczególnie w sytuacjach nieoficjalnych. Równie często jednak używane są zwroty signore, signora i signorina. Ważne jest zidentyfikowanie rozmówcy:

[...] nawet zdawkowe przepraszam musi brzmieć: Scusa 'Przepraszam cię' lub Scusi 'Przepraszam Pana, Panią'; podobne różnice dzielą pożegnanie Arrivederci 'Do widzenia tobie' i ArrivederLa 'Do widzenia Panu, Pani' (Sobolewska, 2005, s. 128).

W Hiszpanii (PDI 57\%) występują obie formy: „ty” i „pan”/,pani”, natomiast w języku portugalskim (PDI 63\%), system zaimków honoryfikatywnych jest bardziej złożony. W języku tym, w sytuacjach małego dystansu używa się zaimka você, będącego formą pośrednią między tu i senhor/a. Zwracając się do osób nieznajomych, używamy zaimka zerowego (cf. Adamska, Waluch-de la Torre, 2005, s. 146).

We Francji (PDI 68\%) najczęściej używanym zwrotem jest zwrot vous, choć można przejść z kimś „na ty” (tu), nie pytając go nawet o zgodę. Przyzwolenie na zwracanie się do kogoś po imieniu postrzegane jest we Francji jako oznaka przyjaźni i bliskości kontaktów. Istnieje tam również forma pośrednia: możemy używać czyjegoś imienia łącząc je z zaimkiem vous. O dużym dystansie do władzy we Francji świadczyć może to, iż możliwa jest sytuacja, gdy przełożony zwraca się do podwładnego po imieniu, natomiast podwładny do szefa per „pan” (cf. Tomaszkiewicz, 2005, s. 12-13).

Kraje arabskie $^{2}$ są jednymi z krajów o największym dystansie do władzy (PDI 80\%). W krajach tych najczęściej używany jest zwrot hadratuka 'twoja obecność'. Jednak w zależności od kraju zwrot ten przybiera różne formy. W Egipcie jest to siyattak 'twoja pańskość', w Iraku dżanabak 'twoje stanowisko', jak również aghati 'mój panie', galbi 'moje serce' i jeni 'oko moje' (cf. Danecki, 2005, s. 240 - 241). Użyty zwrot odnosi się do profesji, funkcji czy pozycji odbiorcy:

Do ludzi starszych bardzo powszechne jest zwracanie się hadżdżi 'pielgrzymie'; wyraża się $\mathrm{w}$ ten sposób szacunek, jakim darzy się daną osobę. [...] Do obcokrajowca w Egipcie można się zwracać, używając perskiego wyrazu chawadża 'pan' [...], osoba wykształcona może być tytułowana ma'allim 'nauczyciel', taksówkarz czy rzemieślnik zaś - usta 'szef'. [...] Najwyższy stopień uszanowania jest wyrażany formułką brufisur 'profesor'. [...] Tytuły są używane nie tylko przy formalnych okazjach, ale nawet w rozmowach ludzi, których łączy pewna zażyłość. Jedynie bardzo przyjacielskie spotkania osób młodych, o równym statusie społecznym pozwalają na ograniczenie ceremonialności, ale nie zwalniają z podkreślania więzów przyjaźni (ibid., s. 241).

\footnotetext{
${ }^{2}$ W swoich badaniach Hofstede ujął następujące kraje: Egipt, Irak, Kuwejt, Liban, Libię, Arabię Saudyjską i Zjednoczone Emiraty Arabskie.
} 


\section{Indywidualizm a kolektywizm}

Wymiar ten dotyczy relacji jednostki z grupą, określa wpływ jaki społeczeństwo na nią wywiera i decyduje o tym czy priorytetem we wszelkich działaniach jest dobro jednostki czy dobro grupy (Hofstede, 2000).

Zdecydowanie najbardziej indywidualistycznym krajem świata są Stany Zjednoczone (IDV 91\%). Dla Amerykanów ważne jest utrzymanie dość dużego dystansu interpersonalnego (cf. Hall, 2001). Tak więc w miejscach publicznych zakłócając czyjąś przestrzeń przepraszają, zanim zapalą papierosa pytają się, czy komuś nie będzie to przeszkadzać, a rodzice pytają dzieci czy mogą wejść do ich pokoju (cf. Warakomska, 2005, s. 264 - 273). Dużo angielskich zwrotów podkreśla odrębność jednostki: zwrot Do one's own thing (IDV: UK - 89\%, Australia - 90\%) nie da się w żaden sposób przetłumaczyć na chiński (IDV 20\%) (cf. Hofstede, 2000, s. 127); podobnie słowo personality (ibid., s. 128, za: Hsu, 1948).

Warto zauważyć, że w krajach indywidualistycznych takich jak Wielka Brytania, Australia, czy USA, gdzie panuje kult jednostki, zaimek osobowy w 1 os. lp. piszemy wielką literą. Matki karcąc swoje dzieci wyrażają dezaprobatę właśnie za pomocą zaimka I: I don’t like what you're doing!, a nie tak jak polskie matki bezosobowo: Nie wolno!.

Jednym z najczęściej słyszanych w tych krajach pytań jest pytanie How are you?. W odpowiedzi oczekuje się słów I'm fine, bądź tylko powtórzenia formuły How are you?. Osoby z kultur bardziej kolektywistycznych odpowiedź I'm fine traktują jako nieszczerą. Nic bardziej błędnego, ponieważ zwrot How are you? ma zupełnie inne znaczenie niż chociażby polskie Co tam u ciebie?. Pytanie How are you? nie jest bowiem pytaniem o faktyczny stan rzeczy, a zwrotem grzecznościowym, sposobem powitania, które wyrażać ma szacunek i zainteresowanie pytaną osobą (a nie jej sprawami czy problemami). W „kulturze jednostki” szanuje się swoją i cudzą prywatność do tego stopnia, iż nawet osobiste uwagi na temat współrozmówcy są w rozmowie niepożądane, a zwrot personal remarks jest nacechowany negatywnie (cf. Wierzbicka, 1991, s. 47).

Prywatność ceni się też w Szwecji (IDV 71\%):

[Szwedzi] nie zapytają ile zarabiasz, ile kosztowało auto, willa, urlop, futro. Nietaktem jest zapytanie „Na kogo głosujesz?”. Jeszcze bardziej niegrzeczne jest zapytać Lapończyka o to ile ma reniferów. [...] Pytania szczegółowe, innymi słowy wsadzanie nosa w czyjeś sprawy, są wysoce niestosowne i nietaktowne (Szmilichowski, 2005, s. 208).

Dowodem na to, że w krajach indywidualistycznych postrzega się ludzi jako jednostki, a nie jako część grupy, może być fakt, iż po angielsku do kobiet zwracamy się częściej Miss niż Mrs. Miss wydaje się bardziej neutralne. W innych językach natomiast, na przykład w polskim (raczej pani, niż panna) czy niemieckim (Frau, a nie Fräulein) zwroty bardziej neutralne odwołują się do mężatek.

Przejdźmy teraz do krajów kolektywistycznych. O kolektywizmie wschodniej Europy i północnej Azji świadczyć może użycie zaimka vy (2 os., l. mn.) w języku rosyjskim (IDV 39\%) jako zwrotu grzecznościowego w stosunku do pojedynczej osoby. Rosjanie chcąc zwrócić uwagę nieznajomej osoby, na przykład kelnerki, także używają liczby mnogiej: простите! извините! (2 os., l. mn.).

Fakt, że język polski (IDV 60\%) jest bardziej kolektywny niż język angielski wpływać może na formę dawania rad. Polacy radzą często, nawet gdy nie są o to proszeni, i oczekują, że ich rozmówca za ich radą pójdzie. Rady wyrażane są w trybie rozkazującym: Radzę ci, zrób to! Dobrze ci radzę, idź tam! Radzenie nie jest postrzegane jako coś niewłaściwego, jest to część codziennego życia. W języku angielskim rady są wyrażane bardziej nieśmiało, nie oczekuje się, że zaważą one na decyzji osoby, której się radzi: If I were you I would do it. Why don't you do it? (cf. Wierzbicka, 1991, s. 31 - 32).

Kolektywistycznym językiem jest z pewnością język wietnamski (IDV 20\%): 
An essentially collectivist language, it has no neutral personal pronouns like "I" or "you". To address someone, you have to guess his or her age and thus give him or her the appropriate rank in the family hierarchy, as an uncle, aunt, father, mother, senior or junior sister, and so on (Ngoc, 2004, WWW, 3.03.2007).

Zdecydowanie kolektywistycznymi krajami są kraje arabskie (IDV 38\%). Świadczyć o tym może zwrot powitalny ahlan wa-sahlan 'Bądź/czuj się jak w swojej rodzinie, Niech ci będzie latwo i prosto' lub marhaban 'Witam z otwartym sercem'. W Syrii zwrotem powitalnym (oraz pożegnalnym) jest chatirkon 'szacunek', a w Iraku ya hele (skrót od: ahlan wa-sahlan) (cf. Danecki, 2005, s. 242 - 243). „Muzułmanie często witają się uroczystym as-salamu alajkum 'Pokój niechaj wam będzie', z obowiązkowym „wam”, niezależnie od tego, czy odnosi się to do wielu osób, czy do jednej” (ibid., s. 243). Pożegnania w krajach arabskich są bardzo wylewne: „chętnie okazuje się przykrość, jaką sprawia rozstanie. [...] Podkreśla się konieczność szybkiego ponownego spotkania. Składanie obietnic, układanie planów spotkania ma charakter formalny i wcale nie musi być zrealizowane" (ibid., s. 244).

\section{Kobiecość a męskość}

Jak podaje Hofstede wymiar kobiecości i męskości przeciwstawia potrzebe asertywnego zachowania potrzebie zachowania skromnego i pokornego (2000, s. 136). $\mathrm{W}$ krajach kobiecych najwyższymi wartościami są ciepło i harmonia, natomiast w męskich - siła i walka.

Krajem zdecydowanie kobiecym jest Szwecja (MAS 5\%). Szwedzi rzadko krytykują czy otwarcie negują.

[...] najczęściej uśmiechną się na to, co powiesz, i kiwają głową, jakby się zgadzali. Dopiero przyparci do muru, poproszeni o zajęcie jasnego stanowiska, wypowiedzą swoje zdanie. Ale zrobią to bardzo delikatnie, często w formie zawoalowanej słowami grzecznościowymi i dygresjami wyciągającymi niejako rękę w stronę twojego rozumowania (Szmilichowski, 2005, s. 198).

Szmilichowski (2005, s. 200) podaje przykłady rozmów w parlamencie szwedzkim: „To jest bardzo interesująca propozycja” znaczy „To jest do niczego!”, „Będziemy próbowali ustalić skalę wartości”: „Kłócimy się aż się kurzy!”, a „Wysiłki przewodniczącego grupy parlamentarnej są ze wszech miar imponujące”: „Nie idzie mu zbyt dobrze”. Niechęć Szwedów do otwartego konfliktu widać w szwedzkim sklepie czy restauracji, kiedy nie są zadowoleni z obsługi. W takiej sytuacji nie robią awantury, nawet nie zwracają uwagi. Pozostają chłodni i po prostu do tego miejsca nie wracają. Milczenie, lub brak słów, jest dość częste w Szwecji, dźwięk Hoouuu... jaki wydaje krtań przy głośnym wdechu, to dźwięk oznaczający potwierdzenie. Dodatkowo, w restauracji wyraża akceptację pierwszej $\mathrm{z}$ podanych przez kelnera propozycji (cf. ibid., s. 201 - 202).

Francuzi jako mieszkańcy kraju bardziej kobiecego niż męskiego (43\% MAS), łagodzą krytykę za pomocą zwrotów „wydaje mi się', 'o ile się nie mylę' itd.” (Tomaszkiewicz, 2005, s. 17). Ponadto:

[...] w wypowiedziach o charakterze argumentacyjnym opinie nie mogą być wyrażone w sposób bezceremonialny i kategoryczny, nawet użycie zaimka „ja” może być uznane za natrętne i despotyczne. W publicystyce do zaimka pierwszej osoby liczby pojedynczej mają właściwie prawo tylko niekwestionowane autorytety $\mathrm{w}$ danej dziedzinie. Prace naukowe najczęściej są zredagowane w pierwszej osobie liczby mnogiej (tzw. nous de modestie) lub bezosobowo (Grabowska, 2005, s. 35).

W komunikacji Francuzów widoczne są jednak również cechy męskie. Francuzi uwielbiają dyskutować, wymieniać zdania, przekonywać współrozmówców do swoich racji. 
Osoby małomówne nie cieszą się popularnością, tak jak i ci, którzy unikają sporów i konfliktów. Przyjęte jest przerywanie wypowiedzi, używanie słów wulgarnych, przeklinanie (cf. Tomaszkiewicz, 2005, s. 16).

Ciekawy może wydać się fakt, iż w krajach słowiańskich, które przejawiają więcej cech kobiecych niż kraje germańskie, nazwiska występują $\mathrm{w}$ rodzaju męskim i żeńskim, natomiast $\mathrm{w}$ języku angielskim i niemieckim formy nazwisk są niezależne od płci (cf. Nagórko, 2005, s. 80).

Skromność charakterystyczna dla komunikacji kobiecej widoczna jest w Holandii, (MAS 14\%). Tam „nie wypada się chwalić samemu, [...] nawet ogólnie uznawanymi osiągnięciami czy bogactwem" (Wasylewicz, 2005, s. 163). Tak samo na pochwały reagują Szwedzi (MAS 5\%). Ponadto:

[...] język holenderski jest zadziwiająco ubogi w przekleństwa. Nie istnieją zupełnie przekleństwa złożone i tak malownicze jak na przykład we Włoszech. [...] Najgorszym przekleństwem jest God verdomma, którego nie da się dokładnie przetłumaczyć, a dosłownie oznacza ‘Bóg przeklął (przeklina, przeklnij) mnie' (ibid., s. 168).

Innym kobiecym krajem, w którym przekleństw używa się rzadko jest Szwecja. Najczęściej są to fan, vel 'diabeł’ i helvete 'piekło'. Przekleństwa związane z płcią, tak silnie nacechowane w języku polskim, słyszy się niezmiernie rzadko.

Najbardziej męskim krajem świata jest Japonia (MAS 95\%) i jak na męski kraj przystało w komunikacji w języku japońskim widoczne są nierówności między kobietami a mężczyznami.

Gender differentiation strikes anyone who visits Japan or who studies the Japanese language, which decrees that men use different speech patterns and words (for example boku or ore, for "I") from women (who say watashi or atashi for "I") (Kanayama, Cooper-Chen, 2005, WWW, 05.05.2010).

W męskim kraju, jakim jest Wielka Brytania (MAS 66\%), na rozmowie o pracę należy podkreślać swoje walory. W kraju tym „docenia się fakt, że ktoś jest świadom swej wartości. Szukając pracy, nie ukrywa się rzeczywistych kwalifikacji, przeciwnie - chwali się dobrą szkołą, dobrymi wynikami czy specjalistycznym wykształceniem” (Szostkiewicz, 2005, s. 97). Brytyjczykom nie jest również obce używanie przekleństw.

Innym męskim krajem, w którym tolerowane są przekleństwa są Włochy (MAS 70\%). „Dosadne wyrażenia [...] o ile są stosowane $\mathrm{z}$ wyczuciem, nie dyskredytują nadawcy. Przeciwnie, nadają konwersacji atmosferę swobody, opartej na szczerości uczuć i odwadze sądów" (Sobolewska, 2005, s. 126).

Również Węgrzy (MAS 88\%) przejawiają cechy męskie. Przeprasza tylko osoba słabsza. „Rodzice nie przepraszają dzieci nawet za oczywiste błędy, mąż nie przeprasza żony. Podobne stosunki panują w pracy" (Berenyine Sztanko, Sztankone Stryjniak, 2005, s. 185).

\section{$5 \quad$ Unikanie niepewności}

Czwarty wymiar mówi o „stosunku do tego, co jest trudno przewidywalne” (Hofstede, 2000, s. 176), o umiejętności radzenia sobie z niepokojem.

Krajem o stosunkowo niskim unikaniu niepewności jest USA (UAI 46\%). Amerykanie nie tworzą ostrych reguł poprawnego zachowania językowego, skomplikowanych form grzecznościowych czy tytułów. Uważa się wręcz, że „używanie tytułów jest sztuczne” (Warakomska, 2005, s. 269). Uwielbiają oni niespodzianki i urządzają sobie nawzajem w sekrecie urodzinowe przyjęcia, krzycząc Surprise!, kiedy podstępem zwabiony jubilat pojawi się w miejscu imprezy. Stany Zjednoczone są dość tolerancyjnym krajem, Amerykanie nie odczuwają niepokoju napotykając odmienność. Na ścieżkach rowerowych 
nie ma znaków, ani tabliczek. „Wszyscy wiedzą, że należy ustępować sobie nawzajem, a piesi nie wchodzą w drogę rowerzystom" (ibid., s. 281).

W języku angielskim ważną rolę w komunikacji pełnią tzw. tag questions, czyli pytania rozłączne. Mają one na celu upewnienie się czy rozmówca się z nami zgadza: Close the window, will/won't/could/can't/would you?. W języku polskim (UAI 93\%) są one rzadkie i znaczą co innego niż angielskie: Idziemy na basen, nie/prawda/tak/co/dobrze? Zdaje się, że Polak szuka potwierdzenia dla tego co mówi (cf. Wierzbicka, 1991, s. 27-38).

Jednym z krajów o największym współczynniku unikania niepewności jest Japonia (UAI 92\%). Przekonać się o tym mogą nauczyciele w japońskich szkołach: uczniowie decydują się odpowiadać na pytania dopiero wtedy, gdy mogą wypowiadać się za całą grupę, w innym wypadku czują się zbyt zagrożeni, boją się (cf. Atkins, 2000, WWW, 3.03.2007).

Innym krajem o silnym unikaniu niepewności jest Francja (UAI 86\%). Może być to powodem francuskiej skłonności do krytykowania innych kultur, ksenofobii oraz problemów z imigrantami pochodzenia arabskiego i afrykańskiego (przywołać tu można chociażby zamieszki z listopada 2005). Francuzom często zarzuca się niechęć do mówienia po angielsku.

Również Niemcy unikają niepewności, choć nie aż tak silnie jak Francuzi. Obrazować to może ich stosunek do niespodzianek oraz znaczenie i użycie słowa Überraschung. Nagórko podaje przykłady:

Sie schossen auf den Transporter und flüchteten in einem gestohlenen Auto. Überraschung, Überraschung! Ma się wrażenie, że kategoria Überraschung nie jest szczególnie ceniona w kulturze niemieckiej. Kojarzy się ona najczęściej z niemiłym zaskoczeniem niż z radosną niespodzianką, i nic dziwnego, jej najczęstszym określeniem jest w niemczyźnie słowo böse 'zły': böse Überraschung (2005, s. 83).

Mieszkańcy krajów o wysokim poziomie unikania niepewności dużo gestykulują, mówią szybko, nierzadko podniesionym głosem. Bez problemu rozmawiają o swoich uczuciach i emocjach. Przykładem takiego kraju mogą być Włochy (UAI 75\%).

\footnotetext{
Rozmowa po włosku jest żywiołowa i głośna. Zwyczaj komunikowania się przyciszonym głosem $\mathrm{w}$ miejscach publicznych jest czymś zgoła nieznanym. Wtajemniczanie postronnych słuchaczy w szczegóły swojego życia rodzinnego czy uczuciowego nie jest rzeczą, która Włochów przeraża. Dzieje się tak być może dlatego, że właściwi adresaci tych wynurzeń bywają równie przypadkowi, co niekiedy licznie zgromadzona publiczność (Sobolewska, 2005, s. 124).
}

Przy pierwszym spotkaniu z nowopoznaną osobą, Włosi często wypytują ją nie tylko o imię i nazwisko, ale także o pochodzenie. Takie zachowanie, może być próbą stłumienia narastającego niepokoju. Otwartość na nowe, bliskie znajomości redukuje niepokój związany z kontaktami z nieznajomymi, a żywiołowość i pewne ciągłe pobudzenie utrzymuje osoby o silnym unikaniu niepewności $\mathrm{w}$ pełnej mobilizacji do walki $\mathrm{z}$ ewentualnym, niezidentyfikowanym zagrożeniem. Gestykulacja i głośne zachowanie dają im poczucie panowania nad sytuacją.

\section{Wnioski}

Interpretacja powyższych przykładów oparta jest na najbardziej wyrazistych cechach danej kultury. Należy pamiętać, iż na wybór słów wpływa wiele czynników, po części formujących kulturę, takich jak klimat, szerokość geograficzna, poziom rozwoju gospodarczego czy doświadczenia historyczne, po części cechy osobowe konkretnych nadawców. Często różnice pomiędzy dwoma językami tłumaczyć można za pomocą więcej niż jednego wymiaru. Aby móc wysnuć jednoznaczne wnioski na temat wpływu kultury 
narodowej na grzeczność w języku należałoby przeanalizować dziesiątki czy wręcz setki tekstów zawierających interesujące nas zwroty. Niemniej jednak biorąc pod uwagę wielość wyżej przedstawionych przykładów przypuszczać można, iż hipoteza stanowiąca o dużym wpływie kultury na grzeczność w języku zostałaby podczas takiej analizy potwierdzona. 


\section{Bibliografia}

1. Adamska, Agata, Waluch-de la Torre, Edyta. 2005. Grzeczność iberyjska a polska. W: Marcjanik, Małgorzata (red.). Grzeczność nasza i obca. Wydawnictwo Trio, Warszawa, s. 133-152.

2. Berenyine Sztanko, Ella, Sztankone Stryjniak, Elżbieta. 2005. Grzeczność po węiersku. W: Marcjanik, Małgorzata (red.). Grzeczność nasza i obca. Wydawnictwo Trio, Warszawa, s. 183-196.

3. Charciarek, Andrzej. 2005. Porównanie wybranych językowych form grzecznościowych polskich, czeskich i rosyjskich. W: Marcjanik, Małgorzata (red.). Grzeczność nasza i obca. Wydawnictwo Trio, Warszawa, s. 103-122.

4. Danecki, Janusz. 2005. Grzeczność w świecie arabskim. W: Marcjanik, Małgorzata (red.). Grzeczność nasza i obca. Wydawnictwo Trio, Warszawa, s. 239-250.

5. Grabowska, Monika. 2005. Francuzi $w$ oczach polskich licealistów. W: Marcjanik, Małgorzata (red.). Grzeczność nasza i obca. Wydawnictwo Trio, Warszawa, s. 25-42.

6. Hall, Edward. 2001. Ukryty wymiar. Muza SA, Warszawa.

7. Hofstede, Geert. 2000. Kultury i organizacje. Zaprogramowanie umystu [Cultures and organizations : software of the mind]. Tłum. Małgorzata Durska. Polskie Wydawnictwo Ekonomiczne, Warszawa.

8. Hofstede, Geert. Geert Hofstede ${ }^{\mathrm{TM}}$ Cultural Dimensions. 05.05.2010, http://www.geert-hofstede.com/index.shtml

9. Hsu, Francis. 1948. Under the Ancestors' Shadow: Chinese Culture and Personality. Columbia University Press, New York.

10. Kanayama, Tomoko, Cooper-Chen, Anne. 2005. Hofstede's Masculinity / Femininity Dimension and the Pregnancy of Princess Masako: An Analysis of Japanese and International Newspaper. Keio Communication Review Nr 27. 05.05.2010, http://www.mediacom.keio.ac.jp/publication/pdf2005/review27/kanayama.pdf

11. Marcjanik, Małgorzata (red.). Grzeczność nasza i obca. Wydawnictwo Trio, Warszawa.

12. Nagórko, Alicja. 2005. Grzeczność wasza i nasza. W: Marcjanik, Małgorzata (red.). Grzeczność nasza i obca. Wydawnictwo Trio, Warszawa, s. 69-86.

13. Ngoc, Huu. 2004. Traditional Miscellany. Viet Nam News. 3.03.2007, http://vietnamnews.vnanet.vn/2004-08/28/Columns/Traditional\%20Miscellany.htm

14. Szmilichowski, Andrzej. 2005. Dym z komina squsiada. Grzeczność po szwedzku. W: Marcjanik, Małgorzata (red.). Grzeczność nasza i obca. Wydawnictwo Trio, Warszawa, s. 197-218.

15. Szostkiewicz, Adam. 2005. „Hello, how are you”. Angielska grzeczność nieodświętna. W: Marcjanik, Małgorzata (red.). Grzeczność nasza i obca., Wydawnictwo Trio, Warszawa, s. 87-102.

16. Tomaszkiewicz, Teresa. 2005. Grzeczność francuska na tle koncepcji grzeczności językowej. W: Marcjanik, Małgorzata (red.). Grzeczność nasza i obca. Wydawnictwo Trio, Warszawa, s. 11-24.

17. Tomiczek, Eugeniusz. 2005. Grzeczność nasza i niemiecka. W: Marcjanik, Małgorzata (red.). Grzeczność nasza i obca. Wydawnictwo Trio, Warszawa, s. 43-68.

18. Warakomska, Dorota. 2005. Grzeczność w Stanach Zjednoczonych. W: Marcjanik, Małgorzata (red.). Grzeczność nasza i obca. Wydawnictwo Trio, Warszawa, s. 263-282.

19. Wasylewicz, Jacek. 2005. Grzeczność holenderska $w$ oczach Polaka. W: Marcjanik, Małgorzata (red.). Grzeczność nasza i obca. Wydawnictwo Trio, Warszawa, s. 153-174.

20. Wierzbicka, Anna. 1991. Cross-Cultural Pragmatics The Semantics of Human Interaction. Mouton de Gruyter, Berlin, Nowy Jork, s. 25-65. 